\title{
China Domestic Test and Verification Research of Wet Grip Performance of C1 Tire Based on ECE R117
}

\author{
Rongliang LIANG ${ }^{1, a^{*}}$, Lin YUAN ${ }^{1, b}$, Mingqiu GAO ${ }^{1, C}$ \\ ${ }^{1}$ China Automotive Technology and Research Center, Tianjin, China \\ aliangrongliang@catarc.ac.cn, byuanlin@catarc.ac.cn, ${ }^{\mathrm{C}}$ gaomingqiu@catarc.ac.cn,
}

Keywords: ECE R117; C1 tire; Wet grip performance; Test and verification

Abstract. The test method for C1 tire wet grip performance based on European ECE R117 is analyzed, combined with the characteristics of China domestic proving ground, the test and evaluation process and test ability for $\mathrm{C} 1$ tire wet grip performance has already been established, which has great reference significance for the formulation standard for the test evaluation and classification of tire performance.

\section{Preface}

The tire imported into EU market must meet the requirements of ECE R117 except requiring the regular ECE R30 and ECE R54 from Oct. 12009 according ECE R117 issued by Economic Commission for Europe (ECE) on April 6, 2005. The European Commission also issued the related tire label regulation EC 1222/2009 which requests that the tire sold in EU must be labeled in order to indicate the classification of tire rolling resistance, wet grip performance and rolling noise exactly according ECE R $117^{[1]}$, meanwhile, the testing and certification for snow tire and special tire labeled Alpine become more and more mature.

With the business expansion of some famous international tire enterprises (Michelin) in domestic market, all kinds of advanced tire test methods, such as tire wear resistance, tire limited adhesion condition, rolling resistance, tire environmental performance, tire comfort performance and tire snow and ice grip performance, have been adopted by domestic tire enterprises. The tire comprehensive performance evaluation becomes stricter in domestic tire enterprises such as Zhongce Rubber and MAXXIS, and the service need for tire testing and certification becomes more and more strong combined with the large scale of domestic vehicles and tires exportation to USA and EU.

The related national standards of tire wet braking, rolling resistance, rolling noise, though issued by Chinese government, are all recommended standards other than compulsory execution, and the related standards have not been implied completely due to lack of SRTT and test site. The vehicle test centers focus on the field of whole vehicle testing and certification, the tire test centers focus on the field of tire testing and certification, therefore, there is no one quality supervision and inspection center which can qualify full scale testing ability completely.

Tire wet grip performance testing method using an instrumented passenger car by ECE R117

\section{Type of tire by ECE R117}

Class C1 tires: Tires conforming to ECE Regulation No.30 ${ }^{[2]}$. In case of tires submitted for approval of performance adhesion on wet surfaces, whether normal tires or snow tires with a speed 
category of Q or below excluding $\mathrm{H}(\leq 160 \mathrm{~km} / \mathrm{h})$ or speed category R and above including H ( $>160$ $\mathrm{km} / \mathrm{h}$ );

Class C2 tires: Tires conforming to ECE Regulation No.54 ${ }^{[3]}$ and identified by a load capacity index in single formation lower or equal to 121 and a speed category symbol higher or equal to "N";

Class C3 tires: Tires conforming to ECE Regulation No. 54 and identified by: A load capacity index in single formation higher or equal to 122; or A load capacity index in single formation lower or equal to 121 and a speed category symbol lower or equal to "M".

To new pneumatic tires of Class $\mathrm{C} 1$ with regard to adhesion performance on wet surfaces (wet adhesion). It does not, however, apply to:

Tire designed as "Temporary use spare tire" and marked "Temporary use only";

Tire having a nominal rim diameter code $\leqslant 10$ (or $\leqslant 254 \mathrm{~mm})$ or $\geqslant 25$ (or $\geqslant 635 \mathrm{~mm}$ );

Tire designed for competitions;

Tire intended to be fitted to road vehicles of categories other than $\mathrm{M}, \mathrm{N}$ and $\mathrm{O}$;

Tire fitted with additional devices to improve traction properties;

Tire with a speed rating less than $80 \mathrm{~km} / \mathrm{h}$;

Tire designed only to be fitted to vehicles registered for the first time before 1 October 1990;

Professional off-road tire for the requirements on rolling resistance and rolling sound.

\section{Type of Standard Reference Test Tire (SRTT)}

\section{SRTT 14" for C1 tire}

This specification covers the general requirements for the P195/75R14 radial standard reference test tire according to ASTM E1136-2010“Standard Specification for P195/75R14 Radial Standard Reference Test Tire" " ${ }^{[4]}$. The tire covered by this specification is primarily for use as a reference tire for braking traction, snow traction, and wear performance evaluations, but may also be used for other evaluations, such as pavement roughness, noise, or other tests that require a reference tire. This method adopted by ECE R117 uses the reference tire that has the characteristics indicated in the ASTM E 1136 and referred to as SRTT14", the average peak braking force coefficient (PBFC) of the SRTT14" shall be $0.7 \pm 0.1$ at $65 \mathrm{~km} / \mathrm{h}$.

\section{SRTT 16" for C1 tire}

This specification covers the general requirements for the P225/60R16 97S radial standard reference test tire according to ASTM F2493-2008 "Standard Specification for P225/60R16 97S Radial Standard Reference Test Tire" [5]. SRTT 16" has been used as reference tire during the wet grip performance for $\mathrm{C} 1$ tire according to ECE R 117.

\section{SRTT 16" for C2 tire}

This specification covers the general requirements for the 225/75R16C 116/114S radial standard reference test tire according to ASTM F2872-2011 "Standard Specification for 225/75R16C 116/114S M+S Radial Light Truck Standard Reference Test Tire" [6]. This SRTT 16" for $\mathrm{C} 2$ tire will be used as reference tire during the wet grip performance for $\mathrm{C} 2$ tire according to ISO 15222-2011 "Truck and bus tire-Method for measuring relative wet grip performance-Loaded new tire". 


\section{SRTT 19.5', for C3 tire}

This specification covers the general requirements for the 245/70R19.5 136/134M radial standard reference test tire according to ASTM F2871-2011 "Standard Specification for 245/70R19.5 136/134M Radial Truck Standard Reference Test Tire" " ${ }^{\text {[] }}$. This SRTT 19.5" for C3 tire will be used as reference tire during the wet grip performance for C3 tire (section width is less than $285 \mathrm{~mm}$ ) according to ISO 15222-2011“"Truck and bus tire-Method for measuring relative wet grip performance-Loaded new tire".

\section{SRTT 22.5', for C3 tire}

This specification covers the general requirements for the 315/70R22.5 154/150L radial standard reference test tire according to ASTM F2870-2011 "Standard Specification for 315/70R22.5 154/150L Radial Truck Standard Reference Test Tire" ${ }^{[8]}$. This SRTT 22.5" for C3 tire will be used as reference tire during the wet grip performance for $\mathrm{C} 3$ tire (section width is more than $285 \mathrm{~mm}$ ) according to ISO 15222-2011“"Truck and bus tire-Method for measuring relative wet grip performance-Loaded new tire" ${ }^{[9]}$.

\section{An instrumented passenger car used for testing}

The testing method covers a procedure for measuring the deceleration performance of $\mathrm{C} 1$ tire during braking, using an instrumented passenger car equipped with an Antilock Braking System (ABS), where 'instrumented passenger car' means a passenger car that is fitted with the measuring equipment for the purpose of this testing method. Starting with a defined initial speed, the brakes are applied hard enough on four wheels at the same time to activate the ABS. The average deceleration is calculated between two pre-defined speeds.

Meanwhile, the instrumented passenger car wheelbase should be less than $3.5 \mathrm{~m}$ when equipped with $\mathrm{C} 1$ tires, and permitted modifications on the passenger car are as follows:

Those allowing the number of tire sizes that can be mounted on the vehicle to be increased;

Those permitting automatic activation of the braking device to be installed;

Any other modification of the braking system is prohibited.

\section{Test condition}

\section{Conditioning of test track}

The surface shall have a dense asphalt surface with a uniform gradient of not more than 2 per cent and shall not deviate more than $6 \mathrm{~mm}$ when tested with a $3 \mathrm{~m}$ straight edge. The surface shall have a pavement of uniform age, composition and wear. The test surface shall be free of loose material and foreign deposits. The maximum chipping size shall be $10 \mathrm{~mm}$ (tolerances permitted from $8 \mathrm{~mm}$ to $13 \mathrm{~mm}$ ). The texture depth as measured by a sand patch shall be $0.7 \pm 0.3 \mathrm{~mm}$. It shall be measured in accordance with ASTM E 965-96 (Reapproved 2006).

The test track surface shall be watered at least half an hour prior to testing in order to equalize the surface temperature and water temperature. External watering should be supplied continuously throughout testing. For the whole testing area, the water depth shall be $1.0 \pm 0.5 \mathrm{~mm}$, measured from the peak of the pavement. The test track should then be conditioned by conducting at least ten test runs with tire not involved in the test program at $90 \mathrm{~km} / \mathrm{h}$. 


\section{Atmospheric conditions}

The wind conditions shall not interfere with wetting of the surface (wind-shields are allowed). Both the wetted surface temperature and the ambient temperature shall be between $2{ }^{\circ} \mathrm{C}$ and $20^{\circ} \mathrm{C}$ for snow tire and $5^{\circ} \mathrm{C}$ and $35^{\circ} \mathrm{C}$ for normal tire. The wetted surface temperature shall not vary during the test by more than $10^{\circ} \mathrm{C}$. The ambient temperature must remain close to the wetted surface temperature; the difference between the ambient and the wetted surface temperatures must be less than $10^{\circ} \mathrm{C}$.

\section{Tires and rims}

The test tire shall be trimmed to remove all protuberances on the tread surface caused by mould air vents or flashes at mould junctions.

The test tire shall be mounted on the test rim declared by the tire manufacturer. A proper bead seat should be achieved by the use of a suitable lubricant. Excessive use of lubricant should be avoided to prevent slipping of the tire on the wheel rim.

The test tire/rim assemblies shall be stored in a location for a minimum of two hours such that they all have the same ambient temperature prior to testing. They should be shielded from the sun to avoid excessive heating by solar radiation. For tire break-in, two braking runs shall be performed.

The static load and inflation pressure on each axle tire are shown in table 1 . Tire loads on the same axle should not differ by more than 10 percent, and tire pressure should be checked just prior to testing at ambient temperature and adjusted if required.

Table 1 the static load on each axle tire and the inflation pressure

\begin{tabular}{|c|c|c|}
\hline Tire type & Inflation pressure $/ \mathrm{kPa}$ & Static load $/ \mathrm{kg}$ \\
\hline SRTT & 220 & $60 \sim 90 \%$ of tested tire load capacity \\
\hline Tested tire & 220 & $60 \sim 90 \%$ of tested tire load capacity \\
\hline
\end{tabular}

\section{Test procedure}

\section{Test run}

The passenger car is driven in a straight line up to $85 \pm 2 \mathrm{~km} / \mathrm{h}$. Once the passenger car has reached $85 \pm 2 \mathrm{~km} / \mathrm{h}$, the brakes are always activated at the same place on the test track referred to as 'braking starting point', with a longitudinal tolerance of $5 \mathrm{~m}$ and a transverse tolerance of $0.5 \mathrm{~m}$.

The brakes are activated either automatically or manually. The manual activation of the brakes depends on the type of transmission as follows. In both cases, a minimum of $600 \mathrm{~N}$ pedal efforts is required.

For manual transmission, the driver should release the clutch and depress the brake pedal sharply, holding it down as long as necessary to perform the measurement.

For automatic transmission, the driver should select neutral gear and then depress the brake pedal sharply, holding it down as long as necessary to perform the measurement.

The average braking distance measured between $80 \mathrm{~km} / \mathrm{h}$ and $20 \mathrm{~km} / \mathrm{h}$ is used to calculate the mean fully developed deceleration (MFDD), as shown in the following formula:

$\mathrm{MFDD}=231.48 / \mathrm{S}$

Where:

MFDD is the mean fully developed deceleration, unit of which is $\mathrm{m} / \mathrm{s}^{2} . \mathrm{S}$ is the braking distance measured between $80 \mathrm{~km} / \mathrm{h}$ and $20 \mathrm{~km} / \mathrm{h}$, unit of which is meter. 
If any of the specifications listed above (including speed tolerance, longitudinal and transverse tolerance for the braking starting point, and braking time) are not met when a test run is made, the measurement is discarded and a new test run is made.

\section{Test cycle}

A number of test runs are made in order to measure the wet grip index of a set of candidate tire according to the following procedure, whereby each test run shall be made in the same direction and up to three different set of candidate tire may be measured within the same test cycle.

The set of reference tires are mounted on the instrumented passenger car. After at least three valid measurements have been made, the set of reference tires are replaced by a set of candidate tires. After six valid measurements of the candidate tires are performed, two more set of candidate tires may be measured. The test cycle is closed by three more valid measurements of the same set of reference tires as at the beginning of the test cycle. Therefore, there are three kinds of test cycle as shown in the following:

R1-T1-R2, R1-T1-T2-R2 and R1-T1-T2-T3-R2

Where:

$\mathrm{R} 1$ is the initial test of the SRTT; R2 is the repeat test of the SRTT; T1, T2 and T3 stand for three different set of candidate tires to be evaluated.

\section{Processing and validation of test results}

For each set of tested tires (both reference tires and candidate tires), the mean and standard deviation of the MFDD shall be computed and reported separately. The coefficient of variation (CV) of one set of tested tires shall be less than 3 percent, calculated as the following formula:

$$
\mathrm{CV}=(\text { Std.dev/Mean }) * 100 \%
$$

Where:

$\mathrm{CV}$ is the coefficient of variation; Std.dev is the Standard deviation of MFDD; and Mean is the average of MFDD.

The weighted adjusted MFDD of SRTT to be used in the comparison of the performance of the candidate tire has been shown in the following table 2 according to the positioning of each candidate tire set in a given test cycle.

Table 2 the weighted adjusted MFDD of SRTT

\begin{tabular}{|c|c|c|}
\hline Test cycle & $\begin{array}{l}\text { mean MFDD of candidate tire } \\
\left(\mathrm{m}^{\left.-\mathrm{s}^{-2}\right)}\right.\end{array}$ & $\begin{array}{l}\text { weighted adjusted MFDD of SRTT } \\
\left(\mathrm{m} . \mathrm{s}^{-2}\right)\end{array}$ \\
\hline R1-T1-R2 & $\mathrm{t}_{1}$ & $\left(\mathrm{R}_{1}+\mathrm{R}_{2}\right) / 2$ \\
\hline \multirow{2}{*}{$\mathrm{t} 1-\mathrm{t} 1-\mathrm{T} 2-\mathrm{R} 2$} & $\mathrm{t}_{1}$ & $2 / 3 \mathrm{R}_{1}+1 / 3 \mathrm{R}_{2}$ \\
\cline { 2 - 3 } & $\mathrm{t}_{2}$ & $1 / 3 \mathrm{R}_{1}+2 / 3 \mathrm{R}_{2}$ \\
\hline \multirow{3}{*}{$\mathrm{R} 1-\mathrm{t} 1-\mathrm{T} 2-\mathrm{T} 3-\mathrm{R} 2$} & $\mathrm{t}_{1}$ & $3 / 4 \mathrm{R}_{1}+1 / 4 \mathrm{R}_{2}$ \\
\cline { 2 - 3 } & $\mathrm{t}_{2}$ & $1 / 2\left(\mathrm{R}_{1}+\mathrm{R}_{2}\right)$ \\
\cline { 2 - 3 } & $\mathrm{t}_{3}$ & $1 / 4 \mathrm{R}_{1}+3 / 4 \mathrm{R}_{2}$ \\
\hline
\end{tabular}

\section{Where:}

$t$ is the actual average of MFDD for the candidate tire to be evaluated. $t_{1}, t_{2}, t_{3}$ stand for the three different sets of candidate tire, $\mathrm{R}_{1}$ is the average of MFDD in the first test of the reference tire set (R1) and $\mathrm{R}_{2}$ is the average of MFDD in the second test of the reference tire set (R2). 


\section{Calculation of the wet grip index of the candidate tire}

The average braking force coefficient of candidate tire set are calculated and adjusted in the following table 3 according to the positioning of each candidate tire set in a given test cycle.

Table 3 the average braking force coefficient of candidate tire

\begin{tabular}{|c|c|c|}
\hline Test cycle & BFC(T) & BFC(R) \\
\hline R1-T1-R2 & $\mathrm{t}_{1} / \mathrm{g}$ & {$\left[\left(\mathrm{R}_{1}+\mathrm{R}_{2}\right) / 2\right] / \mathrm{g}$} \\
\hline \multirow{2}{*}{ R1-T1-T2-R2 } & $\mathrm{t}_{1} / \mathrm{g}$ & {$\left[2 / 3 \mathrm{R}_{1}+1 / 3 \mathrm{R}_{2}\right] / \mathrm{g}$} \\
\cline { 2 - 3 } & $\mathrm{t}_{2} / \mathrm{g}$ & {$\left[1 / 3 \mathrm{R}_{1}+2 / 3 \mathrm{R}_{2}\right] / \mathrm{g}$} \\
\hline \multirow{3}{*}{$\mathrm{R} 1-\mathrm{T} 1-\mathrm{T} 2-\mathrm{T} 3-\mathrm{R} 2$} & $\mathrm{t}_{1} / \mathrm{g}$ & {$\left[3 / 4 \mathrm{R}_{1}+1 / 4 \mathrm{R}_{2}\right] / \mathrm{g}$} \\
\cline { 2 - 3 } & $\mathrm{t}_{2} / \mathrm{g}$ & {$\left[1 / 2\left(\mathrm{R}_{1}+\mathrm{R}_{2}\right)\right] / \mathrm{g}$} \\
\cline { 2 - 3 } & $\mathrm{t}_{3} / \mathrm{g}$ & {$\left[1 / 4 \mathrm{R}_{1}+3 / 4 \mathrm{R}_{2}\right] / \mathrm{g}$} \\
\hline
\end{tabular}

Where:

BFC (T) is the actual average braking force coefficient of candidate tire set, BFC (R) is the weighted average braking force coefficient of reference tire set to be used in the comparison of the performance of the candidate tire set.

The wet grip index of the candidate tire $G(T)$ is calculated as follows:

$$
G(T)=\left[\frac{B F C(T)}{B F C(R)} \times 125+a \times\left(t-t_{0}\right)+b \times\left(\frac{B F C(R)}{B F C\left(R_{0}\right)}-1.0\right)\right] \times 10^{-2}
$$

Where:

$\mathrm{t}$ is the measured wet surface temperature in degree Celsius when the candidate tire $(T)$ is tested;

$t_{0}$ is the wet surface reference temperature condition, $t_{0}=20^{\circ} \mathrm{C}$ for normal tire and $t_{0}=10^{\circ} \mathrm{C}$ for snow tire;

$\mathrm{BFC}\left(\mathrm{R}_{0}\right)$ is the braking force coefficient for the reference tire in the reference conditions, $\operatorname{BFC}\left(\mathrm{R}_{0}\right)=0.68$;

$a=-0.4232$ and $b=-8.297$ for normal tire, $a=0.7721$ and $b=31.18$ for snow tire $[a$ is expressed as $\left.\left(1 /{ }^{\circ} \mathrm{C}\right)\right]$.

\section{The selection of tested vehicle, rims and candidate tires}

\section{tested vehicle selection}

Based on the passenger car class division (as shown in table 4) and their suitable tire specification, the tire section width of class $A_{00}$ 、class $A_{0}$ 、class $A$ 、class $B$ and class $C$ passenger cars covers $175 \mathrm{~mm} 、 185 \mathrm{~mm} 、 195 \mathrm{~mm} 、 205 \mathrm{~mm} 、 215 \mathrm{~mm} 、 225 \mathrm{~mm}$; the nominal rim diameter code covers 14-inch 、15-inch 、16-inch and 17-inch; and the nominal rim width code covers 5.5J、6.0J、 $6.5 \mathrm{~J}$ and $7.0 \mathrm{~J}$. The candidate tires and matched rims are shown in table 5 below. 
Table 4 Passenger car class division

\begin{tabular}{|l|l|l|}
\hline Class & Wheel base $/ \mathrm{m}$ & Engine capacity/L \\
\hline $\mathrm{A}_{00}$ & $2.00 \sim 2.20$ & $<1.0$ \\
\hline $\mathrm{A}_{0}$ & $2.20 \sim 2.30$ & $1.0 \sim 1.3$ \\
\hline $\mathrm{A}$ & $2.30 \sim 2.45$ & $1.3 \sim 1.6$ \\
\hline $\mathrm{B}$ & $2.45 \sim 2.60$ & $1.6 \sim 2.4$ \\
\hline $\mathrm{C}$ & $2.60 \sim 2.80$ & $2.4 \sim 3.0$ \\
\hline $\mathrm{D}$ & $>2.80$ & $>3.0$ \\
\hline
\end{tabular}

Table 5 the candidate tires and matched rims

\begin{tabular}{|l|l|l|l|}
\hline \multirow{2}{*}{ Rim width code/inch } & \multicolumn{3}{|c|}{ Tire section width /mm } \\
\cline { 2 - 4 } & suitable & best & suitable \\
\hline $5.0 \mathrm{~J}$ & 165 & 175 & 185 \\
\hline $5.5 \mathrm{~J}$ & 175 & 185 & 195 \\
\hline $6.0 \mathrm{~J}$ & 185 & 195 & 205 \\
\hline $6.5 \mathrm{~J}$ & 195 & 205 & 215 \\
\hline $7.0 \mathrm{~J}$ & 205 & 215 & 225 \\
\hline $7.5 \mathrm{~J}$ & 215 & 225 & 235 \\
\hline $8.0 \mathrm{~J}$ & 225 & 235 & 245 \\
\hline $8.5 \mathrm{~J}$ & 235 & 245 & 255 \\
\hline $9.0 \mathrm{~J}$ & 245 & 255 & 265 \\
\hline $9.5 \mathrm{~J}$ & 265 & 275 & 285 \\
\hline $10.0 \mathrm{~J}$ & 295 & 305 & 315 \\
\hline $10.5 \mathrm{~J}$ & 305 & 315 & 325 \\
\hline
\end{tabular}

To reflect the wet grip performance of the mainstream $\mathrm{C} 1$ tires assembled to the domestic passenger car objectively and scientifically, the candidate tire section width must cover the above 6 section width series as much as possible. Therefore, one test passenger car is selected from B class division. All the above 6 specification tires can be equipped to the vehicle by the way of upgrading rim and downgrading rim. The parameter of test vehicle is shown in table 6 , and testing site condition is shown in figure 1 and figure 2.

Table 6 the parameter of test vehicle

\begin{tabular}{|l|c|l|c|}
\hline Vehicle & SVW7166GSD & Engine power rating $(\mathrm{kw})$ & 77 \\
\hline Manufacturer & SWV & Curb weight $(\mathrm{kg})$ & $1285738 / 547$ \\
\hline Brand & Octavia & Gross vehicle weight $(\mathrm{kg})$ & $1660848 / 812$ \\
\hline Production & 2012 & Rim code & $16 \times 6.5 \mathrm{~J}$ \\
\hline Engine series & 000930 & Rim PCD $/ \mathrm{mm}$ & $5 \times 112$ \\
\hline VIN & LSVN121Z2C2000535 & Rim center bore diameter $/ \mathrm{mm}$ & 57.1 \\
\hline Vehicle type & M1 & Rim offset $/ \mathrm{mm}$ & 50 \\
\hline
\end{tabular}




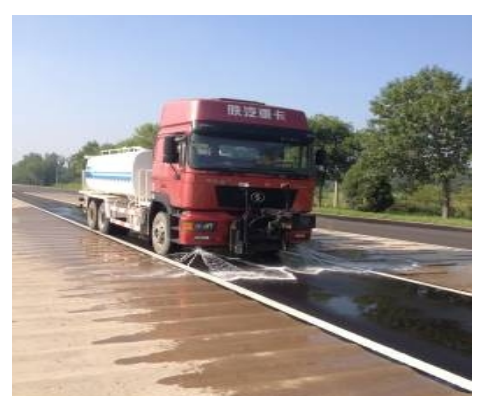

Figure 1 the testing site of wet track

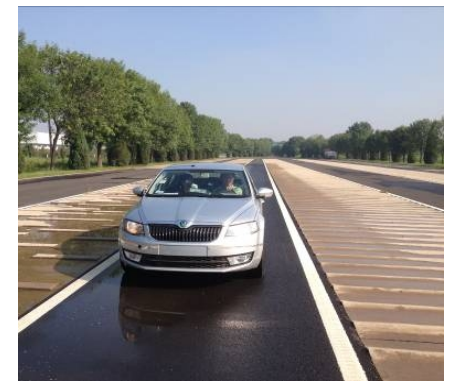

Figure 2 tested vehicle during test

\section{The rims selection}

Octavia passenger car fitted $16 \times 6.5 \mathrm{~J}$ rim code is suitable for tire model $205 / 55 \mathrm{R} 16$, can also be suitable for the tire section width of $185 \mathrm{~mm} 、 195 \mathrm{~mm} 、 205 \mathrm{~mm} 、 215 \mathrm{~mm}$ and $225 \mathrm{~mm}$. The rims and the suitable matched tire model are shown in the following table 7.

To improve the test efficiency and keep test data scientific and impartiality, also to avoid the inefficiency and high resources consumption by the indirect method using intermediate tire as the reference tire, the rim code of $14 \times 6.0 \mathrm{~J}$ is purchased to equip with reference tire model P195/75R14 and candidate tire model 175/65R14, and then the $14 \times 6.0 \mathrm{~J}$ rim is fitted to Octavia test vehicle by adding a $15 \mathrm{~mm}$ thickness of flange to the installation surface to adjust the rim offset.

There will be enough clearance between the original rim and suspension system, between the original tire and fender to allowance $\pm 5 \mathrm{~mm}$ fluctuation of rim offset, therefore, it is not necessary to fit the spacer when the tire section width of $185 \mathrm{~mm} 、 195 \mathrm{~mm} 、 205 \mathrm{~mm} 、 215 \mathrm{~mm}$ and $225 \mathrm{~mm}$ are tested.

Table7 the rims and suitable matched tire model

\begin{tabular}{|l|c|c|c|c|c|c|c|}
\hline Rim code & $14 \times 6.0 \mathrm{~J}$ & $15 \times 6.0 \mathrm{~J}$ & $15 \times 6.5 \mathrm{~J}$ & $16 \times 6.5 \mathrm{~J}$ & $16 \times 7.0 \mathrm{~J}$ & $17 \times 7.0 \mathrm{~J}$ & $17 \times 7.5 \mathrm{~J}$ \\
\hline $\mathrm{PCD} / \mathrm{mm}$ & $5 \times 112$ & $5 \times 112$ & $5 \times 112$ & $5 \times 112$ & $5 \times 112$ & $5 \times 112$ & $5 \times 112$ \\
\hline $\begin{array}{l}\text { Rim center } \\
\text { bore diameter } \\
/ \mathrm{mm}\end{array}$ & 57.1 & 66.6 & 57.1 & 57.1 & 57.1 & 57.1 & 66.4 \\
\hline Rim offset/mm & +38 & +46 & +45 & +50 & +45 & +45 & +45 \\
\hline $\begin{array}{l}\text { Matched tire } \\
\text { model }\end{array}$ & $175 / 65 \mathrm{R} 14$ & $185 / 60 \mathrm{R} 15$ & $195 / 65 \mathrm{R} 15$ & $205 / 55 \mathrm{R} 16$ & $215 / 60 \mathrm{R} 16$ & $225 / 45 \mathrm{R} 17$ & $225 / 45 \mathrm{R} 17$ \\
\hline
\end{tabular}

\section{Candidate tire and SRTT selection}

For the special requirement of domestic market, the selected candidate tires involved 14 sets of candidate tires and 9 mainstream brands, are shown in the following table 8, which covers the tire section width of $175 \mathrm{~mm} 、 185 \mathrm{~mm} 、 195 \mathrm{~mm} 、 205 \mathrm{~mm} 、 215 \mathrm{~mm} 、 225 \mathrm{~mm}$. Based on the selection of the tested vehicle and rims code, the wet grip performance of different mainstream candidate tires is analyzed selectively. P225/60R16 97S radial standard reference test tire specified in ASTM F2493-2008 Standard is adopted as the reference tire according to annex 5 of ECE R117. 
Table 8 the parameters of selected candidate tires

\begin{tabular}{|c|c|c|c|c|c|c|c|}
\hline Tire brand & Hankook & ChaoYang & Bridgestone & Pirelli & Michelin & Continental & ChaoYang \\
\hline Tread patten & Winter icept & SW618 & BLIZZAK REVOGZ & ICECONTROL & X-ICE & Contiviking Contract 5 & SW 608E \\
\hline Snow label & Alps M+S & Alps $\mathrm{M}+\mathrm{S}$ & $\mathrm{M}+\mathrm{S}$ & Alps $\mathrm{M}+\mathrm{S}$ & Alps $\mathrm{M}+\mathrm{S}$ & Alps $\mathrm{M}+\mathrm{S}$ & Alps $\mathrm{M}+\mathrm{S}$ \\
\hline Tire model & $175 / 65 \mathrm{R} 14$ & $175 / 65$ R14 & 185/60R15 & 185/60R15 & $195 / 65 \mathrm{R} 15$ & $205 / 55 \mathrm{R} 16$ & $205 / 55 \mathrm{R} 16$ \\
\hline Rim code & $14 \times 6.0 \mathrm{~J}$ & $14 \times 6.0 \mathrm{~J}$ & $15 \times 6.0 \mathrm{~J}$ & $15 \times 6.0 \mathrm{~J}$ & $15 \times 6.5 \mathrm{~J}$ & $16 \times 6.5 \mathrm{~J}$ & $16 \times 6.5 \mathrm{~J}$ \\
\hline Speed symbol & $Q$ & $\mathrm{~T}$ & $\mathrm{~S}$ & $\mathrm{~T}$ & $\mathrm{~T}$ & $\mathrm{~T}$ & $\mathrm{H}$ \\
\hline Load index & 82 & 82 & 84 & 88 & 95 & 94 & 91 \\
\hline Max.load capacity & 1900 & 1900 & 2000 & 2240 & 2760 & 2680 & 2460 \\
\hline $60 \%$ TLCC & 285 & 285 & 300 & 336 & 414 & 402 & 369 \\
\hline $90 \%$ TLCC & 427.5 & 427.5 & 450 & 504 & 621 & 603 & 553.5 \\
\hline $60 \%$ Max.load capacity & 1140 & 1140 & 1200 & 1344 & 1656 & 1608 & 1476 \\
\hline $90 \%$ Max.load capacity & 1710 & 1710 & 1800 & 2016 & 2484 & 2412 & 2214 \\
\hline Tested vehicle mass/Max.loading capacity & 0.87 & 0.87 & 0.83 & 0.74 & 0.60 & 0.62 & 0.67 \\
\hline Tire brand & LANDSAIL & DoubleCoin & LANDSAIL & DoubleCoin & Pirelli & Hankook & Michelin \\
\hline Tread patten & WINTER LANDER & Warrior WR200 & WINTER LANDER & Warrior WR200 & ICECONTROL & Winter RAFT ice Wi61 & X-ICE \\
\hline Snow label & Alps $\mathrm{M}+\mathrm{S}$ & $\mathrm{M}+\mathrm{S}$ & Alps $\mathrm{M}+\mathrm{S}$ & $\mathrm{M}+\mathrm{S}$ & Alps $\mathrm{M}+\mathrm{S}$ & $\mathrm{M}+\mathrm{S}$ & Alps $\mathrm{M}+\mathrm{S}$ \\
\hline Tire model & $205 / 55 \mathrm{R} 16$ & $205 / 55 \mathrm{R} 16$ & $205 / 55 \mathrm{R} 16$ & $215 / 60 \mathrm{R} 16$ & $225 / 45 \mathrm{R} 17$ & $225 / 45$ R17 & $225 / 45 \mathrm{R} 17$ \\
\hline Rim code & $16 \times 6.5 \mathrm{~J}$ & $16 \times 6.5 \mathrm{~J}$ & $16 \times 6.5 \mathrm{~J}$ & $16 \times 7.0 \mathrm{~J}$ & $17 \times 7.0 \mathrm{~J}$ & $17 \times 7.0 \mathrm{~J}$ & $17 \times 7.5 \mathrm{~J}$ \\
\hline Speed symbol & $\mathrm{H}$ & $\mathrm{T}$ & $\mathrm{H}$ & $\mathrm{T}$ & $\mathrm{T}$ & $\mathrm{R}$ & $\mathrm{H}$ \\
\hline Load index & 91 & 91 & 91 & 95 & 94 & 91 & 94 \\
\hline Max.load capacity & 2460 & 2460 & 2460 & 2760 & 2680 & 2460 & 2680 \\
\hline $60 \%$ TLCC & 369 & 369 & 369 & 414 & 402 & 369 & 402 \\
\hline $90 \%$ TLCC & 553.5 & 553.5 & 553.5 & 621 & 603 & 553.5 & 603 \\
\hline $60 \%$ Max.load capacity & 1476 & 1476 & 1476 & 1656 & 1608 & 1476 & 1608 \\
\hline $90 \%$ Max.load capacity & 2214 & 2214 & 2214 & 2484 & 2412 & 2214 & 2412 \\
\hline Tested vehicle mass/Max.loading capacity & 0.67 & 0.67 & 0.67 & 0.60 & 0.62 & 0.67 & 0.62 \\
\hline $60 \% \sim 90 \% \mathrm{Max}$.loading capacity & \multicolumn{7}{|c|}{$1656 \sim 1710$} \\
\hline Tested vehicle mass & \multicolumn{7}{|c|}{1660 (GVW) $=840$ (Front axle weight) +820 (Rear axle weight) } \\
\hline
\end{tabular}

\section{Pre-preparation before test}

\section{Test vehicle loading}

The vehicle load shall be such that the resulting loads on the tires are between 60 percent and 90 percent of the load corresponding to the tire load index according to Annex 5 of ECE R117, which are shown in table 8 . All the measurement loading information is listed in the table 8 including 60\% TLCC, 90\% TLCC, 60\% Max.load capacity, 90\% Max.load capacity and 60\% 90\%Max.loading capacity. During the whole test cycle, the loading distribution must stick to a unique principle which is "uniform load, changing candidate tire as the same load and same test engineer" to avoid the influence to the test data because of the wave of vehicle load.

\section{The analysis of friction characteristics on the test track}

SRTT P195/75R14 for C1 tires defined in ASTM E1136-93(2003) standard ${ }^{[10]}$ is used to test the friction characteristics on the wet test track according to ISO 8349:2002 ${ }^{[11]}$ and Annex 5 of ECE R117. The tested vehicle first would be accelerated to $85 \mathrm{~km} / \mathrm{h}$ and kept in a stable running condition, and then the power transmission will be disconnected and emergency braking force will be implied on the braking pedal in order to activate ABS system, the braking distance from $80 \mathrm{~km} / \mathrm{h}$ to $50 \mathrm{~km} / \mathrm{h}$ will be used to calculated the average peak braking force coefficient at the speed of $65 \mathrm{~km} / \mathrm{h}$, which are shown in the following table 9 and figure 3. 
Table 9 the friction characteristics of test track by SRTT 14"

\begin{tabular}{|c|r|r|r|r|r|r|}
\hline \multicolumn{4}{|c|}{$\begin{array}{c}\text { Friction characteristics of dry test track } \\
(80-50 \mathrm{~km} / \mathrm{h})\end{array}$} & \multicolumn{3}{c|}{ Friction characteristics of wet test track } \\
\hline Test cycle & $\begin{array}{c}\text { Braking } \\
\text { distance/m }\end{array}$ & PBFC & $\begin{array}{c}\text { Adjusted } \\
\text { PBFC }\end{array}$ & $\begin{array}{c}\text { Braking } \\
\text { distance/m }\end{array}$ & PBFC & $\begin{array}{c}\text { Adjusted } \\
\text { PBFC }\end{array}$ \\
\hline 1 & 24.4 & 0.63 & 0.69 & 20.5 & 0.75 & 0.86 \\
\hline 2 & 25.0 & 0.61 & 0.68 & 19.6 & 0.78 & 0.89 \\
\hline 3 & 25.0 & 0.61 & 0.68 & 20.4 & 0.75 & 0.86 \\
\hline 4 & 25.4 & 0.60 & 0.67 & 20.6 & 0.75 & 0.85 \\
\hline 5 & 26.1 & 0.59 & 0.65 & 19.6 & 0.78 & 0.89 \\
\hline 6 & 24.1 & 0.64 & 0.70 & 20.3 & 0.76 & 0.86 \\
\hline $\begin{array}{l}\text { Validate } \\
\text { value }\end{array}$ & 25.0 & 0.61 & 0.68 & 20.2 & 0.76 & 0.87 \\
\hline
\end{tabular}

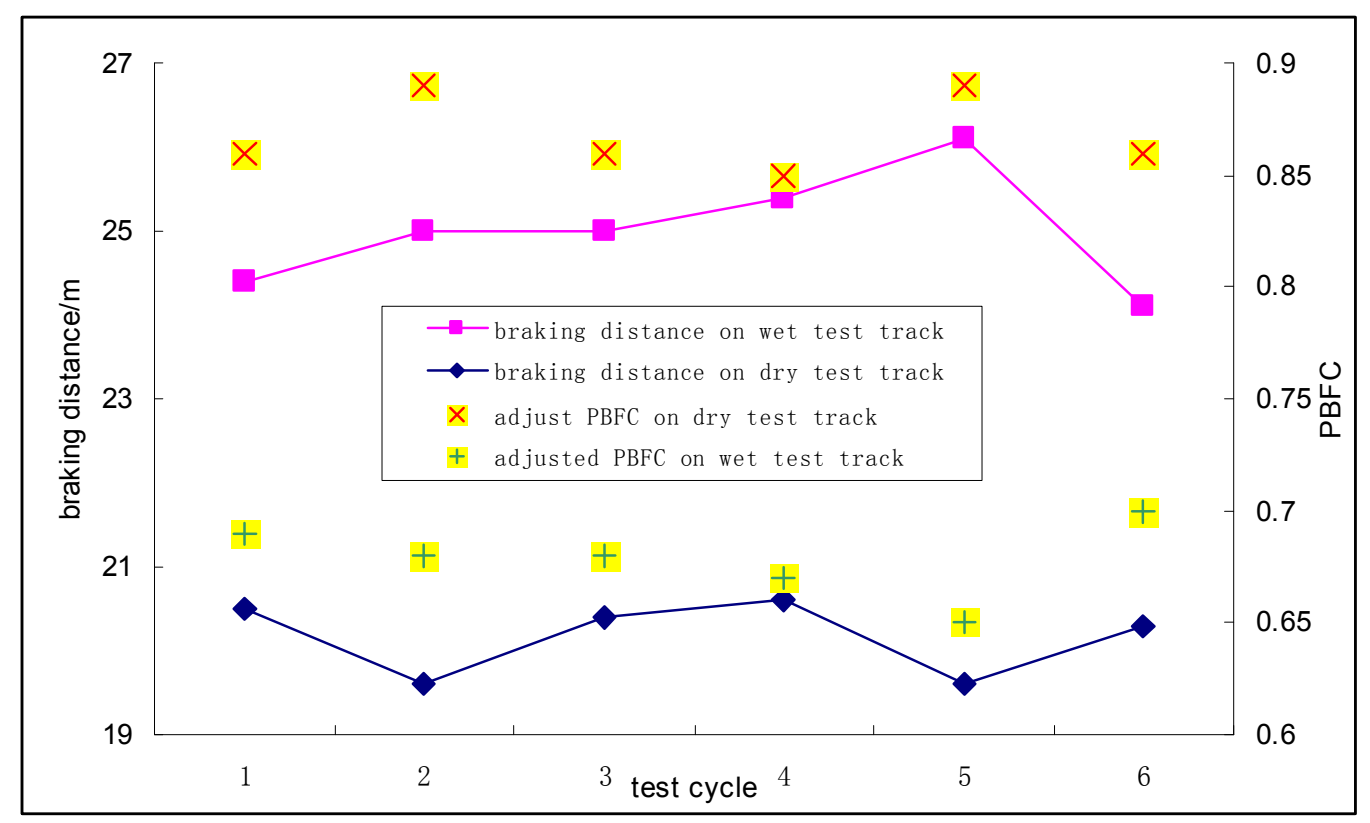

Figure 3 the friction characteristics of test track by SRTT 14"

The PBFC adjusted by the temperature of test track will meet the special friction characteristics requirement of test track if it reaches in range of 0.6 to 0.8 according to Annex 5 of ECE R117. Figure 3 show that the difference of braking distance on wet test track is 2 meters with the tolerance of 8.3 percent, while the difference of braking distance on dry test track is 1 meter with the tolerance of 5.1 percent. The difference of adjusted PBFC on wet test track by temperature is 0.05 , the tolerance between the max and min of which is 7.7 percent, while the difference of adjusted PBFC on dry test track by temperature is 0.04 , the tolerance between the max and min of which is 4.7 percent. Therefore, the friction characteristics of dry test track is more consistent and repeatable than wet test track no matter the braking distance or adjusted PBFC.

\section{Evaluation of wet grip performance}

Form the consideration of intellectual property protection and commercial technical security, 3 sets of candidate tires selected at random from 2 tire brands (LANDSAIL and Double Coin) are tested and evaluated for the wet grip performance, the section width of which covers 205 and 215. 
The results of test data and test evaluation are shown in the following figure 4、 figure 5 and table 10. $\mathrm{T} 1$ stands for the set of candidate tire whose section width is $215 \mathrm{~mm}$; T2 and T3 stand for the two sets of candidate tires, both of which section width are $205 \mathrm{~mm}$.

In order to reduce the influence to the test data because of any occasional changes of test vehicle, test track and meteorological environment during the test, all the test data based on Annex 5 of ECE R117 has been optimized, every one set of candidate tire repeats eight tests, by removing the best and the worst test data and keeping the remain six validate test results using for the following test evaluation, while the reference tire repeats six tests, also removing the best and the worst test data and keeping the remain four validate test results using for the following test evaluation.

Table 10 testing and evaluation of candidate tire

\begin{tabular}{|c|c|c|c|c|c|c|c|c|c|c|}
\hline \multirow{2}{*}{ Testing time } & \multicolumn{5}{|c|}{ Braking distance $/ \mathrm{m}$} & \multicolumn{5}{|c|}{$\operatorname{MFDD} /\left(\mathrm{m} \cdot \mathrm{s}^{-2}\right)$} \\
\hline & R1 & $\mathrm{T} 1$ & $\mathrm{~T} 2$ & $\mathrm{~T} 3$ & $\mathrm{R} 2$ & $R_{1}$ & $t_{1}$ & $t_{2}$ & $t_{3}$ & $R_{2}$ \\
\hline 1 & 33.0 & 34.9 & 32.3 & 31.7 & 33.0 & 7.01 & 6.63 & 7.17 & 7.30 & 7.01 \\
\hline 2 & 31.4 & 35.1 & 30.3 & 31.9 & 31.4 & 7.37 & 6.59 & 7.64 & 7.26 & 7.37 \\
\hline 3 & 32.6 & 36.2 & 31.2 & 32.9 & 32.6 & 7.10 & 6.39 & 7.42 & 7.04 & 7.10 \\
\hline 4 & 31.1 & 34.9 & 31.1 & 32.5 & 31.1 & 7.44 & 6.63 & 7.44 & 7.12 & 7.44 \\
\hline 5 & & 36.0 & 32.1 & 33.2 & & & 6.43 & 7.21 & 6.97 & \\
\hline 6 & & 35.9 & 31.3 & 31.6 & & & 6.45 & 7.40 & 7.33 & \\
\hline Average value & 32.0 & 35.5 & 31.4 & 32.3 & 32.0 & 7.23 & 6.52 & 7.38 & 7.17 & 7.23 \\
\hline \multicolumn{6}{|c|}{ Std.dev } & 0.187 & 0.110 & 0.172 & 0.147 & 0.187 \\
\hline \multicolumn{6}{|c|}{$\mathrm{CV}(\leq 3 \%)$} & 2.58 & 1.68 & 2.33 & 2.05 & 2.58 \\
\hline \multicolumn{6}{|c|}{$\mathrm{BFC}(\mathrm{T})$} & & 0.66 & 0.75 & 0.73 & \\
\hline \multicolumn{6}{|c|}{$\mathrm{BFC}(\mathrm{R})$} & & 0.74 & 0.74 & 0.74 & \\
\hline \multicolumn{6}{|c|}{$\mathrm{G}(\mathrm{T})(\geq 1.07)$} & & 0.98 & 1.12 & 1.08 & \\
\hline
\end{tabular}

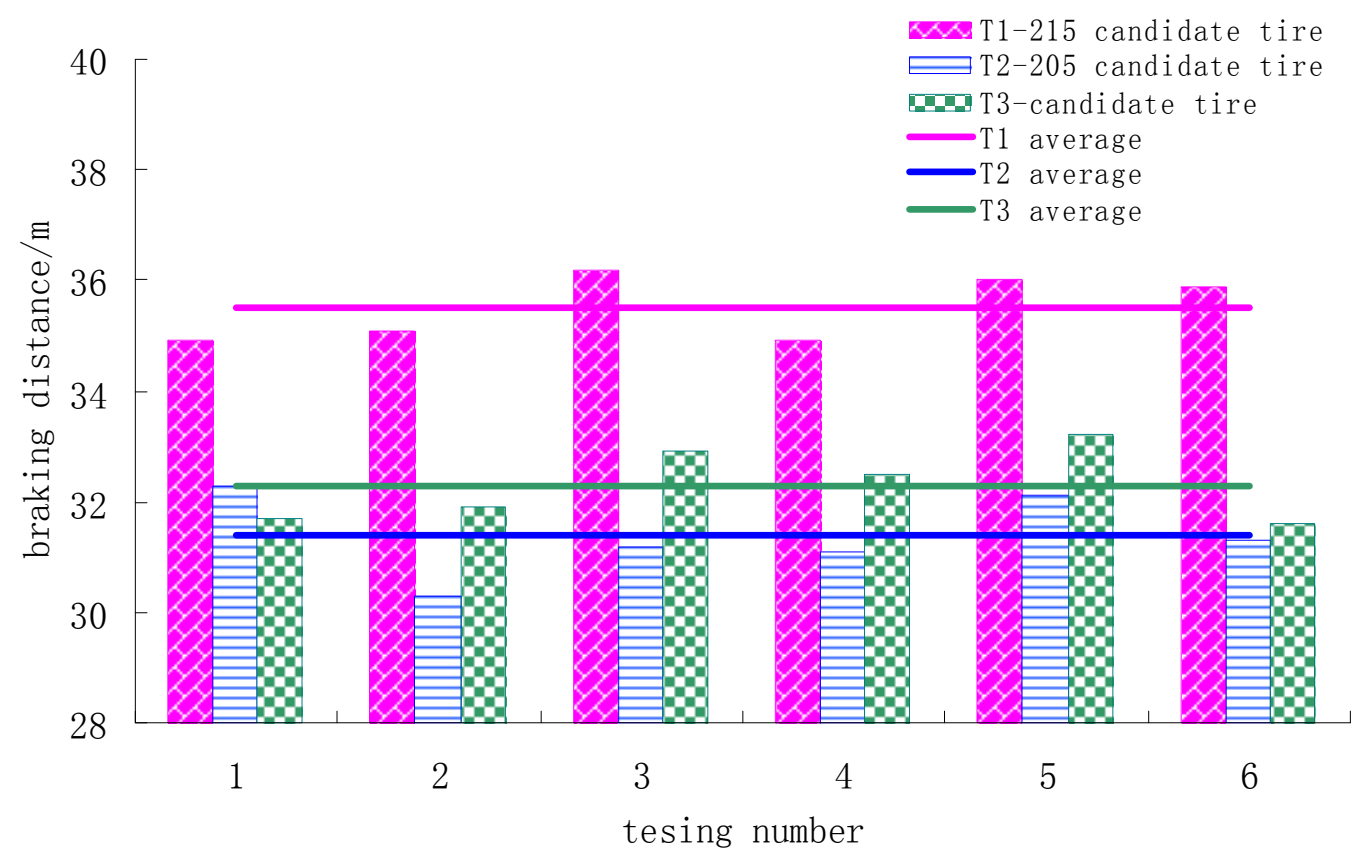

Figure 4 the braking distance of candidate tires 


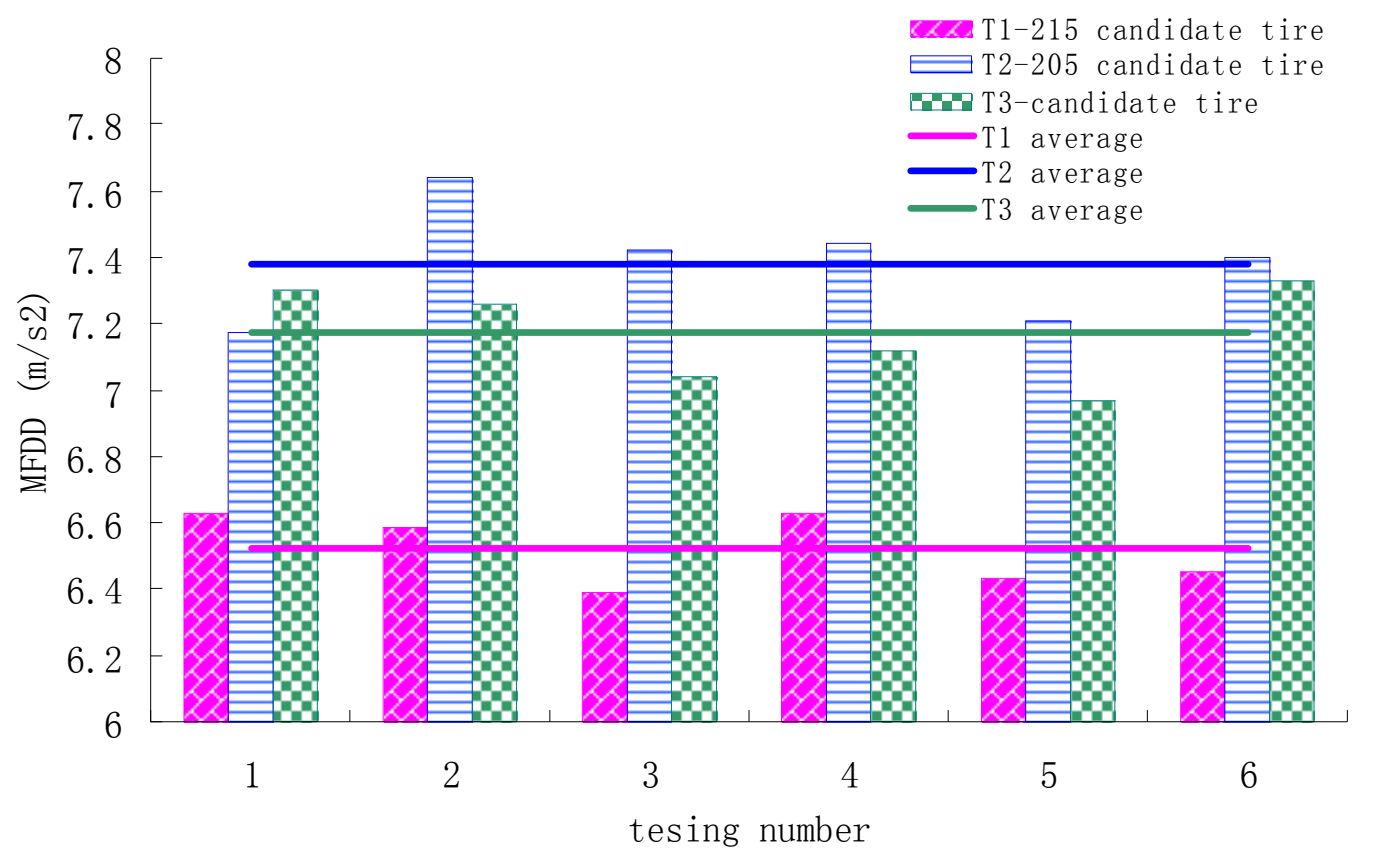

Figure 5 the MFDD of candidate tires

All the test results (ex. Braking distance and MFDD) of both candidate tire and reference tire are consistent and repeatable delicately as shown in table 10, and the validate CV values are less than 3 percent specified by standard test procedure. Figure 4 and figure 5 shows the detail comparison of braking distance and MFDD about all the tested tires. The braking distance difference of $\mathrm{T} 1$ candidate tire between the max and min among the six validate tests is 1.3 meters with the tolerance of 3.7 percent; The braking distance difference of $\mathrm{T} 2$ candidate tire between the max and min among the six validate tests is 2.0 meters with the tolerance of 6.6 percent; while The braking distance difference of $\mathrm{T} 3$ candidate tire between the max and min among the six validate tests is 1.6 meters with the tolerance of 5.1 percent. The MFDD difference calculated by braking distance of $\mathrm{T} 1$ candidate tire is 0.24 with the tolerance of 3.8 percent; The MFDD difference calculated by braking distance of $\mathrm{T} 2$ candidate tire is 0.47 with the tolerance of 6.6 percent; while the MFDD difference calculated by braking distance of $\mathrm{T} 3$ candidate tire is 0.36 with the tolerance of 5.2 percent. Therefore, the tolerance of MFDD is consistent compared with the tolerance of braking distance.

There may be some differences in track residual existed in tire tread and void ratio between different test sequences, which may influences the repeatability of testing and certification. Meanwhile, there may be micro changes of pavement compaction in the braking test track, all of the above index leads to the micro wave of braking distance and MFDD. Therefore, there is 3 percent tolerance of $\mathrm{CV}$ difference during the testing on candidate tire and reference tire.

\section{Conclusions}

Nowadays all kinds of tire are designed and researched by domestic tire manufacturers according to the market requirements. However, the test methods and standards for the wet grip performance are still defective. The EU and USA have already owned their mature technology for the field of $\mathrm{C} 1$ wet grip performance, and the standards for $\mathrm{C} 2$ and $\mathrm{C} 3$ wet grip performance are on 
the process of revision. Therefore, it is necessary to trace and analyze the relevant international standards, which has great reference and guidance significance for the design and research of related products and the relevant standard revision.

All the test research bases on the major scientific research project "The Objective Evaluation System Research on Tire Test", which is a major special Five-year automotive test platform of CATARC. All the objective evaluation indexes of tire test are analyzed deeply, and the relevant evaluation indexes database used for the domestic tire classification is also built during test. The main purpose is to build the tire classification method suitable for the domestic tire condition which can promote the relevant technology improvement.

The tire test of wet grip performance is carried out in CATARC proving ground to build the tire test technical platform shared with domestic tire manufacturers, and to build the technical reserve preparing for enlarging the domestic tire test market and export certification market. The main purpose of tire test is to expand CATARC international influence in the field of tire testing and certification, and to set up the objective evaluation system for tire based on tire regular testing, vehicle and tire performance development, proving ground technical service.

\section{Acknowledgements}

This work was financially supported by the major scientific research project "The Objective Evaluation System Research of Tire Test", which is the major special Five-year automotive test platform of CATARC. Project Series Number is CATARC13140101.

\section{References}

[1] ECE R117-2013 "Uniform Provisions concerning the Approval of Tires with regard to Rolling Sound Emissions and/or to Adhesion on Wet Surfaces and/or to Rolling Resistance";

[2] ECE R30-2007 "UNIFORM PROVISIONS CONCERNING THE APPROVAL OF PNEUMATIC TYRESFOR MOTOR VEHICLES AND THEIR TRAILERS”;

[3] ECE R54-2003“UNIFORM PROVISIONS CONCERNING THE APPROVAL OF PNEUMATIC TYRESFOR COMMERCIAL VEHICLES AND THEIR TRAILERS”;

[4] ASTM E1136-2010“Standard Specification for P195/75R14 Radial Standard Reference Test Tire";

[5] ASTM F2493-2008 "Standard Specification for P225/60R16 97S Radial Standard Reference Test Tire"

[6] ASTM F2872-2011 "Standard Specification for 225/75R16C 116/114S M+S Radial Light Truck Standard Reference Test Tire";

[7] ASTM F2871-2011 "Standard Specification for 245/70R19.5 136/134M Radial Truck Standard Reference Test Tire";

[8] ASTM F2870-2011 "Standard Specification for 315/70R22.5 154/150L Radial Truck Standard Reference Test Tire";

[9]ISO15222:2011“"Truck and bus tire-Method for measuring relative wet grip performance-Loaded new tire";

[10] ASTM E1136-2010 "Standard Specification forP195/75R14 Radial Standard Reference Test Tire";

[11] ISO 8349:2002 "Road vehicles-Measurement of road surface friction"; 